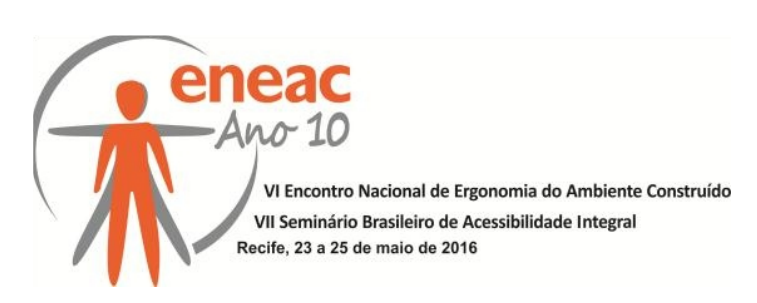

\title{
ADEQUAÇÃO ACÚSTICA DE UM AUDITÓRIO DAS FACULDADES INTEGRADAS DE PATOS NA PARAÍBA
}

\author{
GOMES, Emmily Gérsica Santos (1); BARBOSA, Karoline Lustosa Gadelha (2); \\ SOARES, Bianca de Lucena (3); GRASSI, Matheus Dantas (4)
}

(1) Faculdades Integradas de Patos, Mestra em Arquitetura e Urbanismo-PPGAU/UFPB e-mail: emmilygersica@hotmail.com

(2) Faculdades Integradas de Patos, Graduanda de Arquitetura e Urbanismo e-mail: karolinelustosaa@gmail.com

(3) Faculdades Integradas de Patos, Graduando de Arquitetura e Urbanismo e-mail: biancadelucenasoares@gmail.com

(4) Faculdades Integradas de Patos, Graduanda de Arquitetura e Urbanismo e-mail: matheusearquitetura@gmail.com

\begin{abstract}
RESUMO
Esta pesquisa, resultado de um trabalho da graduação, avalia o desempenho acústico do Auditório de Odontologia das FIP-PB, onde a maior preocupação foi a inteligibilidade do som. Foi realizado o levantamento dos equipamentos e materiais do local, para efeito de análise do tempo de reverberação, como a NBR 12179 (ABNT, 1992) solicita. Os cálculos indicados por norma, desenvolvidos através da equação de Sabine, foram realizados para diferentes frequências. Posteriormente, simulações de introdução de novos materiais, sem intervir na estrutura atual, foram propostos como forma de melhorar o tempo de reverberação atual. Por fim, foi lançada uma proposta de anteprojeto.
\end{abstract}

Palavras chave: Acústica Arquitetônica; Tempo de reverberação; Auditório; Reflexão sonora.

\begin{abstract}
This paper, the result of a disciplinary of graduation, evaluates the acoustic performance of Dental Auditorium of the FIP -PB, where the main concern was the intelligibility of sound .Performed was the lifting of equipment and materials from the site, for effect of analisys of the reverberation team, the NBR 12179 (ABNT, 1992) require. The calculations Indicated by norm, developed by Sabine equation were carried out for different frequencies. After, the introduction of simulations of the new materials, without intervening in the current structure, were proposed in order to improve the present reverberation time. Finally, it was launched the proposal of a draft.
\end{abstract}

Keywords: architectural acoustics ; reverberation time ; auditorium ; sound reflection. 


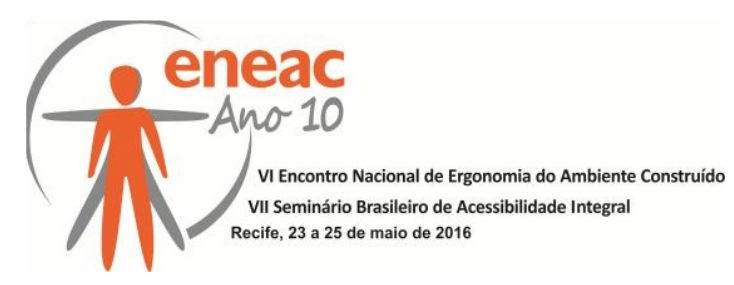

\section{INTRODUÇÃO}

Segundo Souza (2012), a acústica é um elemento de grande importância na utilização dos espaços e deve ser entendida como parte integrante do projeto arquitetônico, seja ele para construção ou reforma de um local. A situação acústica de um ambiente influencia diretamente na sua eficiência enquanto espaço arquitetônico, principalmente quando esse lugar exerce uma função que exige mais qualidade sonora, como um auditório, pois age sobre um dos sistemas mais sensíveis do homem: o ouvido.

Níveis de ruído acima do recomendado podem causar desconforto, cansaço, irritabilidade, distúrbios digestivos e até surdez aos usuários. Porém estes efeitos não são de caráter imediato e sim cumulativo. Outro aspecto importante a ser considerado em uma avaliação acústica de um auditório é o coeficiente de absorção sonora dos materiais que compõe o espaço. Essa absortância influencia diretamente na reverberação, que é o intervalo de tempo necessário para que o nível de intensidade de um determinado som decresça $60 \mathrm{~dB}$, após o termino da emissão de sua fonte.

Os materiais construtivos, os revestimentos, os móveis e a presença das pessoas em um ambiente são fatores que têm grande influência sobre a acústica deste, pois estes possuem diferentes coeficientes de absorção acústica e valores de propagação do som. Para ter um bom desempenho acústico e promover conforto aos usuários, o ambiente necessita promover uma boa inteligibilidade da fala, isso ocorre quando o tempo de reverberação está adequado e os níveis de ruído são baixos.

Em auditórios o desconforto acústico está diretamente ligado à falta de compreensão da fala. Durante palestras e apresentações, ouvintes não compreendendo adequadamente as palavras do orador, podem vir a sentir fadiga e perda de interesse para os audientes.

Diante desta problemática, o objetivo deste trabalho é avaliar se o tempo de reverberação do auditório do bloco de odontologia das Faculdades Integradas de Patos. Para isso, foram identificados os elementos construtivos que contribuem para o desconforto ambiental, também foi avaliada a condição acústica do ambiente, tomando por base as normas técnicas pertinentes. Por fim a pesquisa irá propor um projeto de adequação acústica, sem intervir na estrutura do local, utilizando materiais que se aproximem do Tempo ótimo de reverberação para este ambiente.

\section{ACÚSTICA EM AUDITÓRIOS}

"Para que o conforto acústico seja efetivado dentro das edificações deve existir o controle de ruídos internos e externos em níveis adequados, bem como a inteligibilidade do som e o tempo de reverberação" (MAIA \& SALGADO, 2005).

A reverberação consiste no prolongamento necessário de um som produzido, a título de sua inteligibilidade em locais mais afastados da fonte produtora. Isso se dá basicamente em recintos fechados. Esse prolongamento deverá ser maior quanto maior for à distância entre a fonte e a recepção, ou ainda, quanto maior for o volume interno do recinto. "Ao incidirem em uma superfície, as ondas sonoras são refletidas, absorvidas ou transmitidas em proporção que dependem da dimensão da forma e do material dessa superfície" (SOUZA, ALMEIDA \& BRAGANÇA, 2007).

O tempo de reverberação é uma das características acústicas mais importantes e mais utilizadas na qualificação de um ambiente. "Seu valor pode favorecer ou prejudicar consideravelmente a atividade realizada no ambiente, pois interfere na inteligibilidade da fala ou na qualidade musical" (BERTOLI et al, 2008). O tempo de reverberação é o tempo 


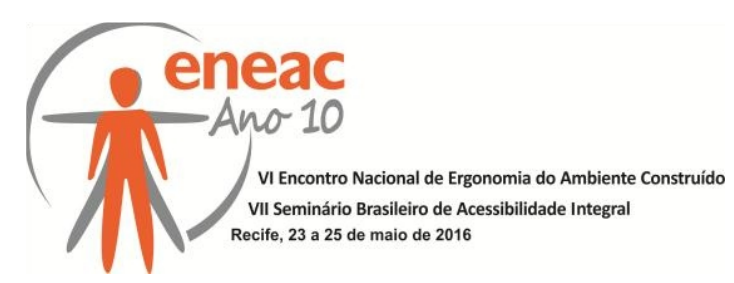

necessário para que o som emitido em um ambiente fechado se torne totalmente inaudível após a fonte sonora ser completamente cessada.

Para Passero (2009) uma definição mais técnica é afirmar que, o tempo de reverberação é o tempo expresso em segundos, necessário para o nível de pressão sonora decrescer $60 \mathrm{~dB}$ em uma taxa de decaimento dada pela regressão dos quadrados lineares da curva de decaimento medido de um nível de $5 \mathrm{~dB}$ abaixo do nível inicial a $35 \mathrm{~dB}$ abaixo do mesmo nível.

Os valores ideais para o tempo de reverberação de um recinto, na sua grande parte, dependem do seu volume e do fim a que se destina. Se for um local em que a palavra é a principal função, por exemplo, uma sala de conferências, o tempo de reverberação deve ser baixo, de modo a manter a inteligibilidade da palavra. Para Long (2006) as variações entre $5 \%$ a $10 \%$ dos valores ideais são aceitáveis

De acordo com Simões (2011) frequência se define como o número de ciclos que a onda sonora completa em um segundo medido em cps ou Hertz, abreviatura $\mathrm{Hz}$, que nos dá a sensação de graves (baixas frequências) e agudos (altas frequências). As normas internacionais indicam que se analisem principalmente os sons compreendidos nas faixas de frequência de $125 \mathrm{Hertz}$ e seus múltiplos, 250, 500, 1000, 2000 e $4000 \mathrm{~Hz}$. Neste trabalho foram analisadas uma frequência média, uma grave e uma aguda.

Grande parte do que se reconhece como essencial na acústica de um auditório pode ser discutido em termos da resposta acústica de um ouvinte. A boa difusão de uma sala é alcançada não só pela forma irregular e difusa de superfícies, mas também pela aplicação balanceada de materiais de construção. "Como cada material apresenta capacidade própria de absorção sonora, sua distribuição influi no tempo de reverberação do lugar" (SOUZA et al, 2012).

De acordo com a NBR 12179: "Tratamento acústico em recintos fechados" (ABNT, 1992), o cálculo do tempo de reverberação se dá a partir da equação de Sabine (Equação 1):

$$
\operatorname{tr}: \frac{0,161 \mathrm{~V}}{\mathrm{~S} 1 \mathrm{a} 1+\mathrm{S} 2 \mathrm{a} 2+\cdots}
$$

Onde:

tr= tempo de reverberação do recinto;

$\mathrm{V}=$ volume do recinto;

Snan = área das superfícies e seu respectivo coeficiente de absorção.

A absorção e reverberação estão intimamente relacionadas ao tipo de frequência do som, portanto, é imprescindível que sejam isoladas frequências distintas, e analisados os comportamentos desses fenômenos nas mesmas, assim, será possível observar a situação atual do comportamento do som em diferentes situações e a partir disto, propor a correção acústica ao ambiente.

De Marco (1982) recomenda que a diferença entre o tempo de ótimo de reverberação e o tempo de reverberação encontrado não pode ser maior que $0,2 \mathrm{~s}$. De acordo com o Regulamento dos Requisitos Acústicos dos Edifícios (RRAE), em recintos cuja principal valência corresponda a atividades assentes na oratória, nomeadamente auditórios, o tempo de reverberação, $\mathrm{T}$, correspondente à média aritmética dos valores obtidos para as bandas de oitava, centradas nas frequências de $500 \mathrm{~Hz}, 1000 \mathrm{~Hz}$ e $2000 \mathrm{~Hz}$. 


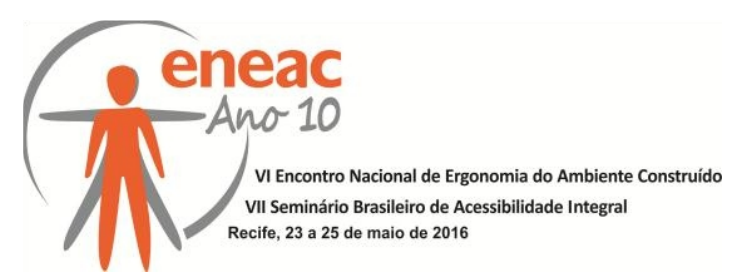

No auditório em estudo a principal atividade desenvolvida é a oratória, então faz-se necessário o uso das frequências da fala: $125 \mathrm{~Hz}, 500 \mathrm{~Hz}$ e $2000 \mathrm{~Hz}$, onde o tempo de reverberação da situação em questão deverá corresponder, seguindo a lógica do RRAE, à média aritmética das frequências anteriormente citadas.

\section{DESCRIÇÃO DO OBJETO DE ESTUDO}

O objeto de estudo é o Auditório de Odontologia das Faculdades Integradas de Patos, que está localizado no Estado da Paraíba, na cidade de Patos. O município está situado no Nordeste do Brasil, na porção mais central da Paraíba, com latitude 0701'28" sul e longitude $37^{\circ} 28^{\prime} 42$ '. Com uma área de $473,056 \mathrm{Km}^{2}$, a cidade conta com 100.674 habitantes (IBGE, 2010).

Localizada no bairro Belo Horizonte a faculdade se limita, ao norte, pela Avenida Horácio Nóbrega, ao sul, pelo Rio Espinharas, ao leste, a Rua Cândido das Laranjeiras e ao oeste por um canal (Figura 1).

Figura 1- (a) Imagem satelite do Bloco de Odontologia das FIP; (b) Fachada Norte do Bloco de Odontologia das FIP.
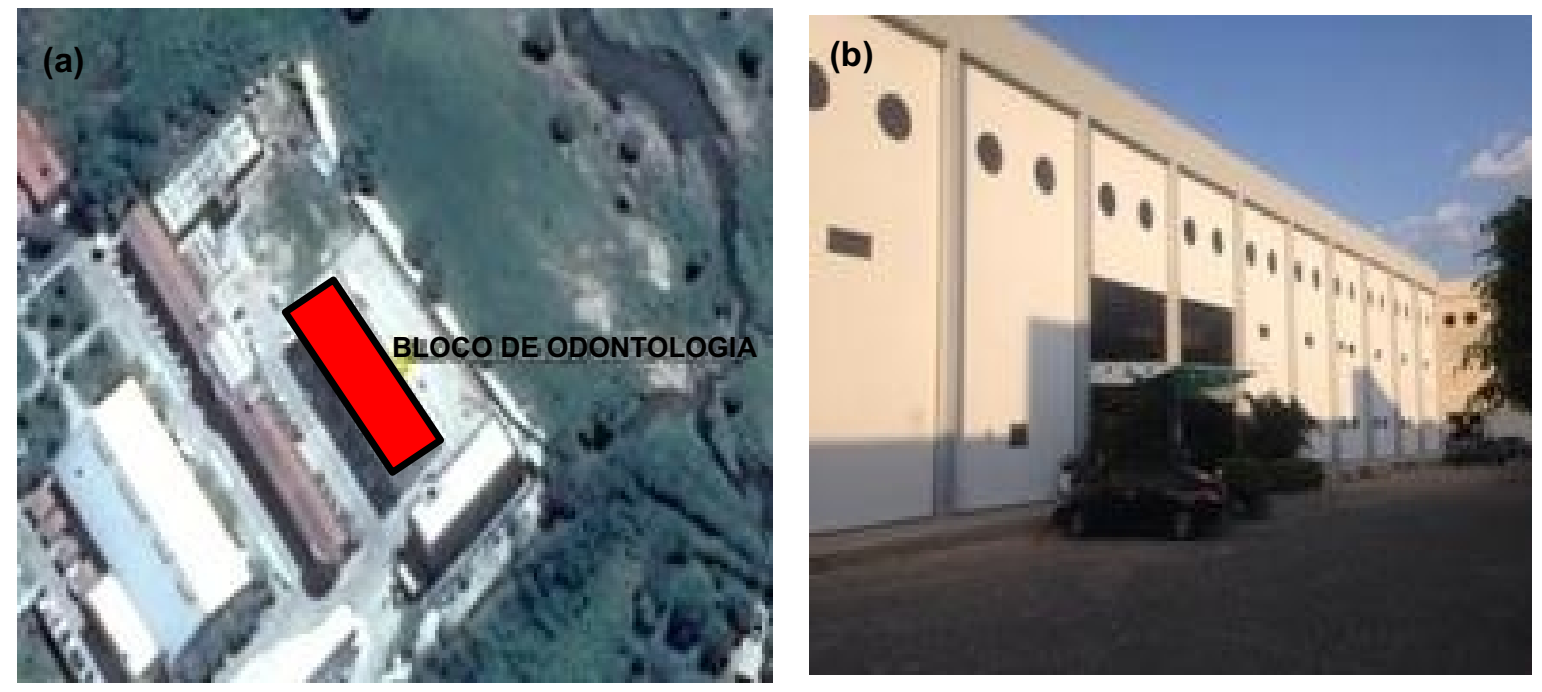

Fonte: (GOOGLE EART, 2016); (AUTORES, 2016).

O auditório está posicionado no segundo andar do bloco de odontologia e possui uma área de $98,04 \mathrm{~m}^{2}$, com forma regular e um pé direto de $2,40 \mathrm{~m}$ e volume de $235,30 \mathrm{~m} 3$. Suas fachadas norte e sul possuem $6,58 \mathrm{~m}$ e a leste e oeste possuem $14,90 \mathrm{~m}$, onde as fachadas sul e oeste confrontam-se de forma direta com o meio externo. O ambiente comporta 132 (cento e trinta e duas) pessoas, distribuídas em 127 (cento e vinte sete) assentos na plateia e 05 (cinco) no palco (Figura 2). 


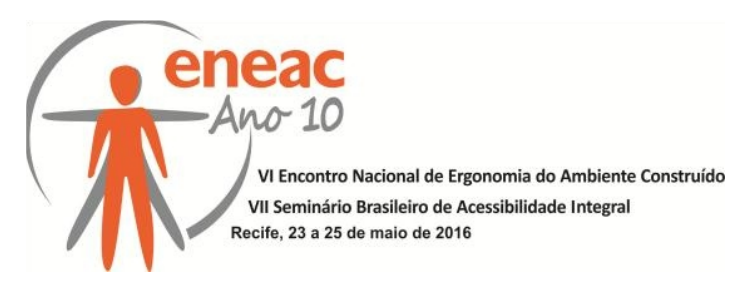

Figura 2- Planta baixa do Auditório de Odontologia das FIP.

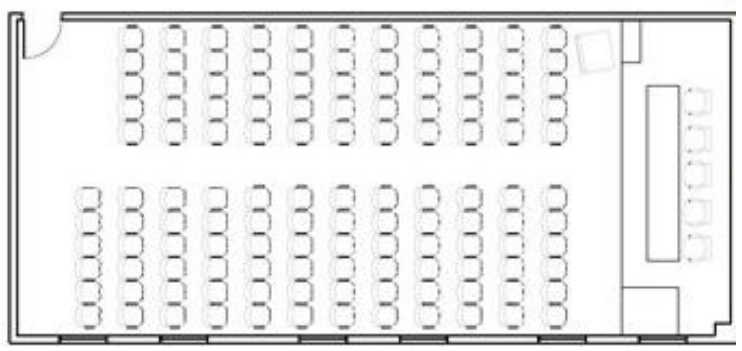

Fonte: (AUTORES, 2016).

\subsection{Elementos Construtivos e Esquadrias}

O auditório é totalmente revestido de tijolo cerâmico e argamassa, nas paredes e pilares. Seu piso é de cerâmica antiderrapante. O teto é constituído por um teto falso em gesso, com uma caixa-de-ar com cerca de $20 \mathrm{~cm}$. O palco é em MDF laminado, onde possui uma rampa revestida por borracha.

\subsection{Equipamentos e Mobiliário}

As cadeiras podem-se considerar como levemente estofadas e revestidas com courine, 0 espaçamento entre filas é de cerca de $80 \mathrm{~cm}$. Existe um púlpito de MDF laminado e uma mesa do mesmo material, que está localizada no palco. A porta é de compensado, revestida com laminado.

\subsection{Iluminação e Climatização}

Possui seis janelas de vidro com plástico adesivo, com diâmetro de um metro. No entanto a iluminação e ventilação encontrada são predominantemente artificiais. Onde possui lâmpadas fluorescentes (12 unidades) no teto por todo o recinto e dois condicionantes de ar.

\section{MÉTODOLOGIA}

\subsection{Etapa 01- Levantamento de Dados}

A primeira etapa realizada foi o levantamento de dados do auditório, onde verificou-se os materiais existentes e o dimensionamento de suas superfícies. Para o registro fotográfico utilizou-se câmera SONY (ILCE-3000K); trena a laser para as medições do mobiliário (mesa, cadeiras, púlpito, palco, luminárias, piso, alvenaria e esquadrias) e as medidas básicas do auditório (área e volume); folhas de rascunho para croqui do auditório e utilização do software AutoCAD 2015 para desenvolvimento da planta baixa e cortes.

\subsection{Etapa 02- Análise de Desempenho Acústico: Estudo da Geometria Local e Cálculo do Tempo de Reverberação (Tr)}

Em seguida foi realizado o cálculo do tempo de reverberação segundo a NBR 12179: "Tratamento acústico em recintos fechados" (ABNT, 1992). Para consulta de alguns conceitos a respeito da problemática do ruído utilizou-se as NBR 10152 (1987) e a NBR 10151 (ABNT, 2000). Entre as seis frequências exigidas por norma, foram estudas 03 (três), 


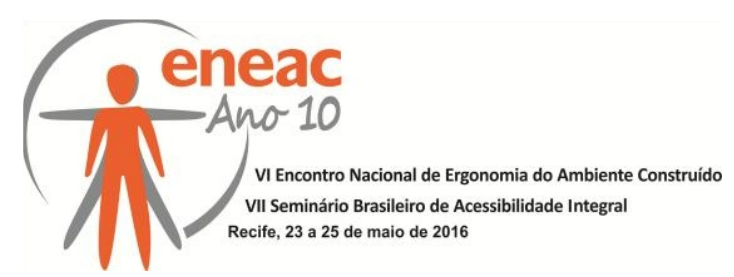

uma representativa para a frequência grave $(125 \mathrm{~Hz})$, média $(500 \mathrm{~Hz})$ e outra para a aguda $(2000 \mathrm{~Hz})$.

Os cálculos foram desenvolvidos através da fórmula de Sabine, que foi inserida em uma planilha no programa Excel, da Microsoft, disponibilizada nas aulas de conforto acústico, e para isso foi necessário o levantamento do coeficiente de absorção sonora de todos os materiais existentes no auditório. Para finalizar esta etapa de análise, realizou-se o estudo da geometria do auditório, como forma de entender a reflexão sonora no ambiente.

\subsection{Etapa 3- Proposta de Condicionamento Acústico}

$\mathrm{Na}$ terceira e última fase foi realizada uma proposta de anteprojeto, após a inserção de diferentes materiais, com os cálculos foi possível identificar o material mais viável para melhorar a acústica do local. Ocorreu a avaliação comparativa através de simulações inserindo diversos materiais para correção acústica do auditório, para obtenção do tempo de reverberação ideal. Por fim, aplicaram-se os novos materiais em um modelo tridimensional produzido no programa Sketchup.

\section{RESULTADOS}

Depois de realizado o levantamento dos materiais existentes no auditório, posteriormente foi registrado as informações, onde esses dados levaram a permitir avaliar e calcular o tempo de reverberação da atual situação do espaço. Na tabela 1 está à descrição dos materiais que se encontram no auditório de Odontologia.

Tabela 1 - Classificação dos elementos analisados do Auditório de Odontologia das FIP.

\begin{tabular}{|c|c|c|}
\hline \multicolumn{3}{|c|}{ CLASSIFICAÇÃo DOS ELEMENTOS ANALISADOS } \\
\hline Elementos & Materiais & Dimensões \\
\hline Cadeira & Courine e Ferro & $0,47 \mathrm{~m} ; 0,42 \times 0,42 \mathrm{~m}$ \\
\hline Janela & Vidro e Plástico Adesivo & Diâmetro: $1,0 \mathrm{~m}$ \\
\hline Parede & Tijolo Cerâmico e Argamassa & $0,15 \mathrm{~m}$ \\
\hline Palco & MDF Laminado e Borracha & $0,30 \mathrm{~m} ; 6,58 \times 2,28 \mathrm{~m}$ \\
\hline Púlpito & MDF Laminado & $1,20 \mathrm{~m} ; 0,55 \times 0,50 \mathrm{~m}$ \\
\hline Porta & Compensado revestido com & $0,80 \mathrm{~m} \times 2,10 \mathrm{~m}$ \\
\hline laminado & Gesso & Espessura: $12,5 \mathrm{~cm}$ \\
\hline Peto & Cerâmica antiderrapante & $0,40 \times 0,40 \mathrm{~m}$ \\
\hline Mesa & MDF e Laminado & $0,80 \mathrm{~m} ; 0,65 \times 3,65 \mathrm{~m}$ \\
\hline
\end{tabular}

Fonte: (AUTORES, 2016). 


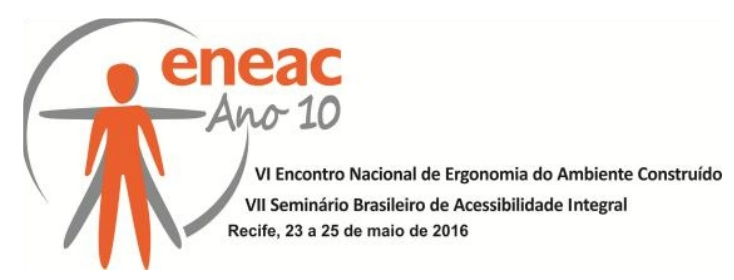

Na Tabela 2 foi aplicada a fórmula de Sabine, o que possibilitou encontrar o tempo de reverberação do ambiente. Com o resultado foi possível observar que o auditório apresenta tempo de reverberação excessivo para a oratória, de acordo com o resultado dos cálculos em comparação com o tempo ótimo de reverberação indicado NBR 12179 (ABNT, 1992).

Tabela 2 - Dados para Análise do tempo de reverberação da situação atual do auditório de odontologia das FIP para as frequências de $500 \mathrm{~Hz}, 125 \mathrm{~Hz}$ e $2000 \mathrm{~Hz}$

\begin{tabular}{|c|c|c|c|c|c|c|c|c|c|}
\hline & litório do Bloco de & Larg. & Com & Alt. & Volur & Ocup. & $\mathrm{V} / \mathrm{O}$ & & tor \\
\hline & & 6,58 & $14, \mathrm{c}$ & 2,4 & 235,3 & 132 & 1 , & & 0,7 \\
\hline & & & $50 C$ & $\mathrm{~Hz}$ & & & & $\mathrm{OHz}$ & \\
\hline & & SI & $\mathbf{i}$ & Si $x i$ & $\mathbf{i}$ & Six i & $\mathbf{i}$ & Si $x$ & $x \quad i$ \\
\hline 1 & Teto de gesso & 92,91 & 0,050 & 4,646 & 0,080 & 7,433 & 0,020 & 1,8 & 358 \\
\hline 2 & $\begin{array}{l}\text { Parede de tijolo cerâmico } \\
\text { revestido com argamassa }\end{array}$ & 96,68 & 0,020 & 1,934 & 0,020 & 1,934 & 0,030 & 2,9 & 00 \\
\hline 3 & $\begin{array}{l}\text { Porta de compensado } \\
\text { revestida com laminado }\end{array}$ & 1,68 & 0,080 & 0,134 & 0,140 & 0,235 & 0,080 & 0,1 & 34 \\
\hline 4 & Esquadria de vidro & 4,74 & 0,04 & 0,190 & 0,180 & 0,853 & 0,030 & 0,1 & 42 \\
\hline 5 & $\begin{array}{l}\text { Piso cerâmica } \\
\text { antiderrapante }\end{array}$ & 83,04 & 0,010 & 0,830 & 0,010 & 0,830 & 0,020 & 1,6 & 61 \\
\hline 6 & $\begin{array}{l}\text { Cadeira estofada com } \\
\text { couro sintético }\end{array}$ & 46,2 & 0,150 & 6,930 & 0,130 & 6,006 & 0,070 & 3,2 & 34 \\
\hline 7 & $\begin{array}{l}\text { Palco em MDF revestido } \\
\text { com laminado }\end{array}$ & 16,89 & 0,180 & 3,040 & 0,250 & 4,223 & 0,100 & 1,6 & 89 \\
\hline 8 & $\begin{array}{l}\text { Púlpito em MDF revestido } \\
\text { com laminado }\end{array}$ & 2,52 & 0,180 & 0,454 & 0,250 & 0,630 & 0,100 & 0,2 & 52 \\
\hline 9 & $\begin{array}{l}\text { Mesa em MDF revestido } \\
\text { com laminado }\end{array}$ & 4,92 & 0,180 & 0,886 & 0,250 & 1,230 & 0,100 & 0,4 & 92 \\
\hline Temp & ótimo de reverberação(s) & & 0,7 & & & & &, 7 & \\
\hline & sorção total calculada & & 19,04 & & & & & 36 & \\
\hline & Absorção ideal & & 54,12 & & & & & ,12 & \\
\hline & $\begin{array}{l}\text { ppo de reverberação } \\
\text { calculado (tr) }\end{array}$ & & 1,99 & & & & & 06 & \\
\hline
\end{tabular}

Fonte: (AUTORES, 2016).

Além do tempo de reverberação foram observados também fatores quanto à forma, como o volume per capita. O volume per capita para salas de conferencia como no caso do auditório 


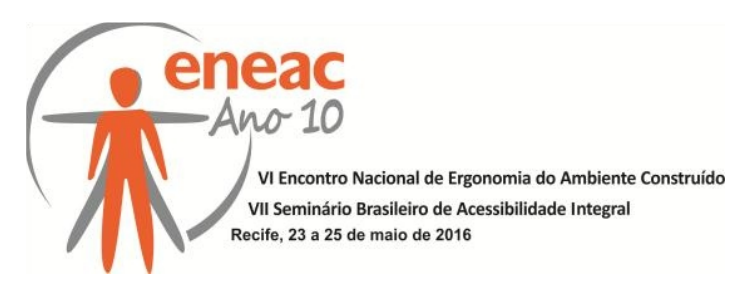

é de $5,14 \mathrm{~m}^{3}$, sendo que o máximo para a atividade é de $4,3 \mathrm{~m}^{3}$. Esse volume impróprio de 1,78 dificulta a correção no tempo de reverberação. Além disso, o auditório apresenta paralelismo entre as paredes laterais e entre a parede do fundo e do palco, podendo causar ondas estacionárias.

Também foi observado que a geometria do local é desfavorável à compreensão da fala (Figura 3), pois existem muitas superfícies reflexivas, onde as ondas sonoras emitidas pelo orador são refletidas pelas superfícies de contato, causando eco. A perda de compreensão foi identificada como sendo responsável pela fadiga, estresse e perda de interesse na oratória por parte do ouvinte, isso tudo pode ser ocasionado pelo excesso de reflexão no ambiente. O eco é um dos fatores que mais comprometem a inteligibilidade, com a mensagem atrasada, comprometendo o aprendizado.

Figura 3 - Estudo da reflexão sonora através da geometria representada no Corte AA do Auditório de Odontologia das FIP

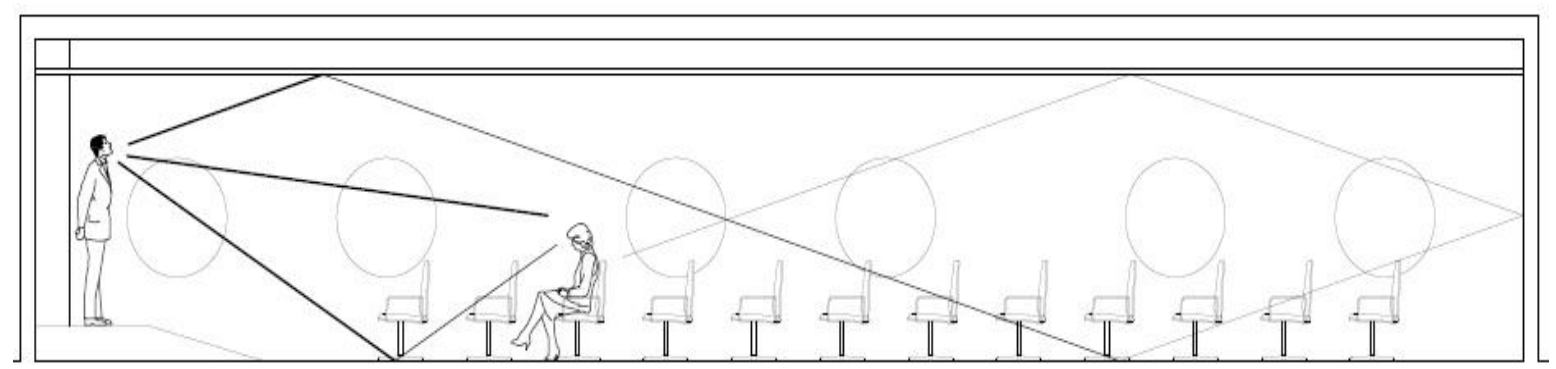

Fonte: (AUTORES, 2016).

A forma dos ambientes deve evitar o desenvolvimento de erros acústicos, como ecos, ondas estacionárias e pontos de intensidade sono insuficiente. $O$ paralelismo deve ser evitado devido a possibilidade de gerar ondas estacionárias. Devem ser evitadas também superfícies côncavas, circulares e elípticas, pois promovem a concentração, a focalização e, consequentemente, a distribuição não uniforme do som. "Para melhorar a distribuição do som podem ser utilizadas superfícies de reflexão sonora, chamados de espelhos acústicos. Esses espelhos devem ser posicionados com ângulos que favoreçam a projeção do som para locais mais prejudicados acusticamente" (SOUZA et al, 2012).

Outro aspecto que deve ser observado na concepção do projeto de auditório é volume do espaço. "Quando o volume do ambiente está de acordo com a função exercida, evita a utilização de materiais absorventes ou refletores que eleva o custo final do projeto" (CARVALHO, 2010).

Com o problema identificado, observou-se as superfícies que estavam mais propícias a alterações, comprometendo em menor valor o custo de uma provável alteração. O projeto propôs a adição de materiais com maior absorção acústica, nas frequências básicas estudadas $(125 \mathrm{~Hz}, 500 \mathrm{~Hz}$ e $2000 \mathrm{~Hz})$. Optou-se por acrescentar dois materiais: o carpete, por todo o piso, por ser um bom absorvente acústico, o que ocasionou a estabilização das frequências agudas e médias; e um quadro à óleo, que favoreceu a frequência grave (Tabela 3). 


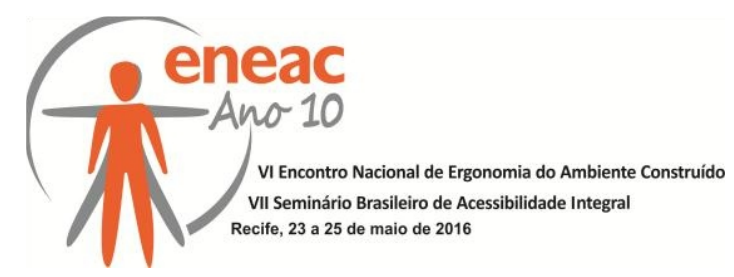

Tabela 3 - Dados para Análise do tempo de reverberação da situação do auditório de odontologia das FIP após alterações para as frequências de $500 \mathrm{~Hz}, 125 \mathrm{~Hz}$ e $2000 \mathrm{~Hz}$.

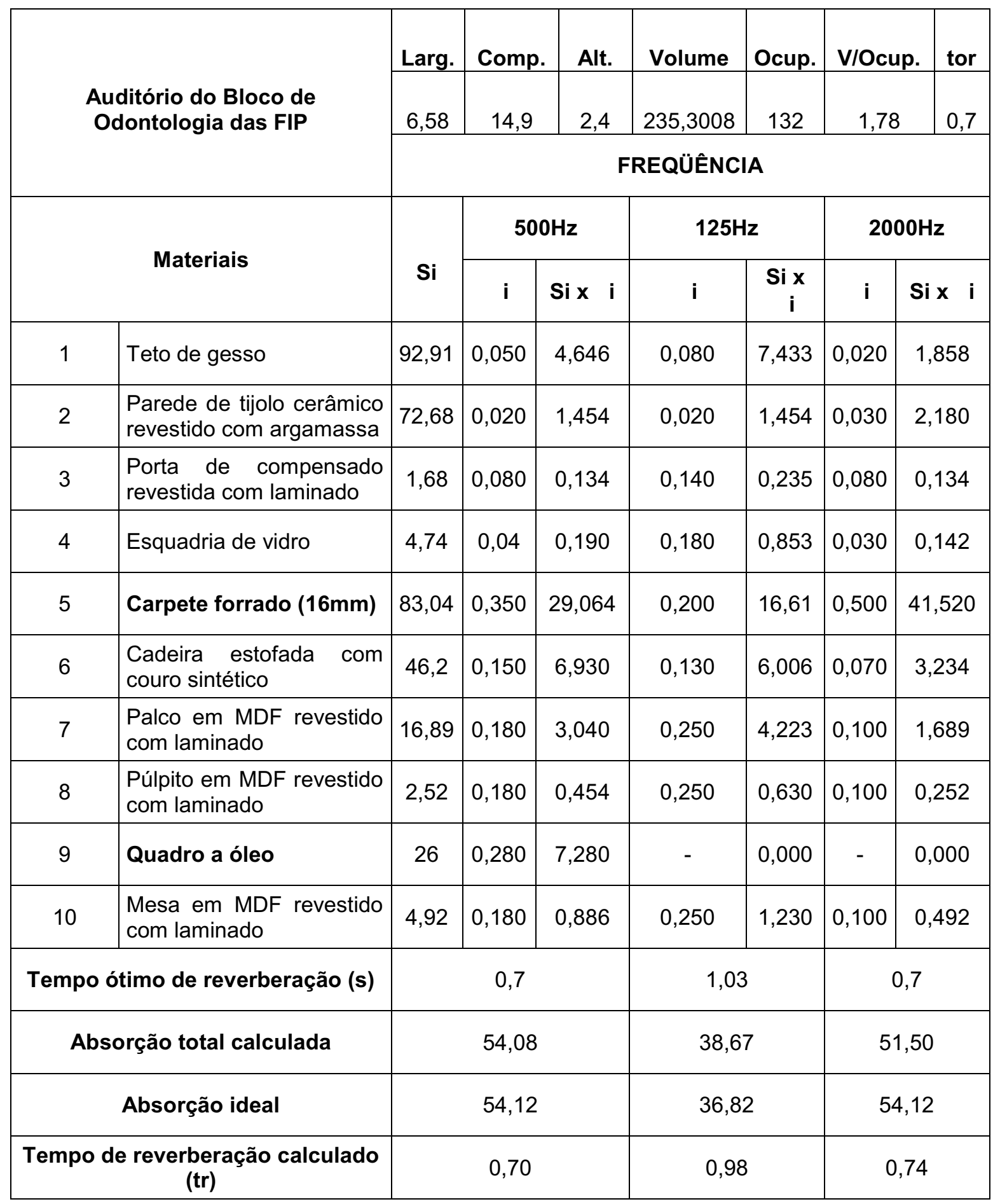

Fonte: (AUTORES, 2016).

Através desses dados é possível perceber que a proposta de intervenção conseguiu corrigir o tempo de reverberação, estando a diferença entre o tempo calculado e o tempo ideal entre os $10 \%$ negativos ou positivos. Com os resultados dos novos materiais empregados, foi produzido no Sketchup um modelo tridimensional da nova proposta do auditório de odontologia (Figura 4). 


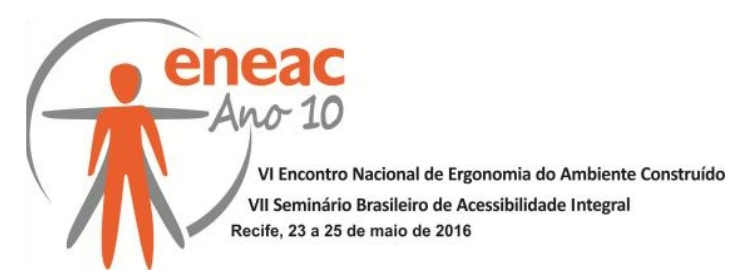

Figura 4 - Modelo tridimensional da nova proposta do Auditório de Odontologia das FIP.
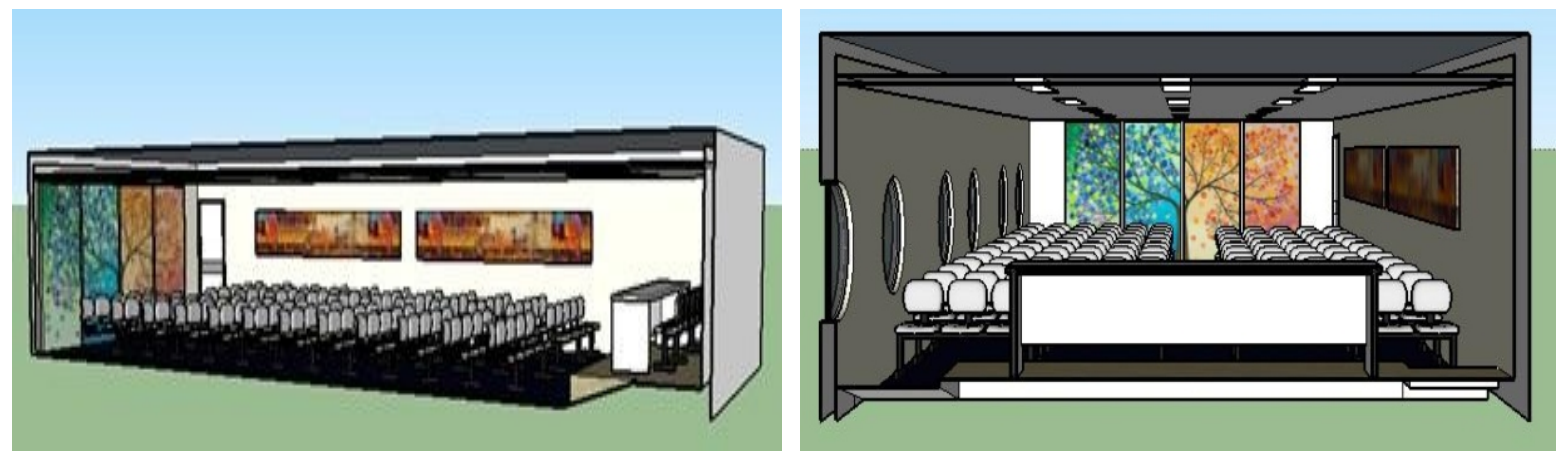

Fonte: (AUTORES, 2016).

A nova proposta de intervenção visou adequar o lugar a condições acústicas ideais, mas também de maneira simples e econômicas. A solução proposta manteve a estrutura do local e o mobiliário preexistente. O material utilizado absorveu a energia sonora das ondas excessivamente longas. Onde eliminou o problema do alto valor do tempo de reverberação, melhorando a compreensão da fala e livre de ecos.

\section{CONCLUSÕES}

A pesquisa foi realizada através de simulações com a introdução de novos materiais, sem intervenção na estrutura, onde proporcionou diversas possibilidades de correção do tempo de reverberação, onde foi possível chegar a um valor aproximando do tempo ótimo de reverberação recomendado para o auditório.

A maior dificuldade da pesquisa foi encontrar o índice correto de absorção de cada material existente no auditório, e, a conclusão dos cálculos, onde, ao adicionarmos algum material absorvente, se corrigia o tempo de reverberação em uma frequência, porém as demais permaneciam inadequadas, ou seja, foi trabalhoso alcançar o tempo ótimo de reverberação para as três frequências ao mesmo tempo.

O estudo do tempo de reverberação é importante, pois além de ajudar nas atividades exercidas no local, pode contribuir para diagnosticar se o mesmo ambiente se encontra dentro do padrão exigido pelas normas e, caso este não se encontre, propor soluções que adequem o tempo de reverberação do local, melhorando seu desempenho acústico. A presente pesquisa demonstrou que é possível melhorar o desempenho acústico de um ambiente, com baixo custo, através de propostas simples, se observado o que as normas vigentes e a literatura indicam para o desenvolvimento de um projeto acústico.

\section{REFERÊNCIAS BIBLIOGRÁFICAS}

ASSOCIAÇÃO BRASILEIRA DE NORMAS TÉCNICAS. NBR 10151: Acústica - Avaliação do ruído em áreas habitadas, visando o conforto da comunidade - Procedimento. Rio de Janeiro, 2000.

ASSOCIAÇÃO BRASILEIRA DE NORMAS TÉCNICAS. NBR 10152: Níveis de ruído para conforto acústico. Rio de Janeiro, 1987.

ASSOCIAÇÃO BRASILEIRA DE NORMAS TÉCNICAS. NBR 12179: Tratamento Acústico em 


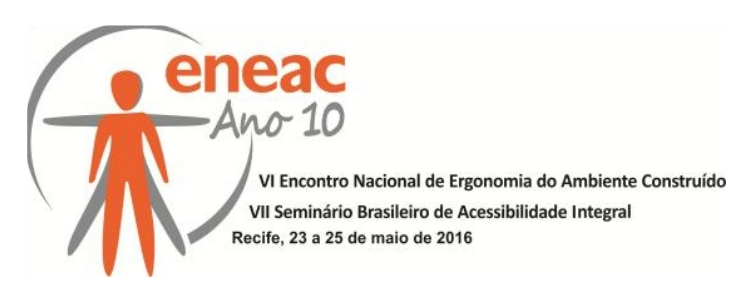

Recintos Fechados. Rio de Janeiro, 1992.

CARVALHO, Régio Panagio. Acústica Arquitetônica. Ed. Thesauros. Brasília, 2010.

DE MARCO, C.S. Elementos da acústica arquitetônica. São Paulo: Nobel, 1982.

LONG, Marshall. Architectural Acoustics. s.I. : Elsevier Academic Press, 2006.

MAIA, M. L.; SALGADO, M.S. Qualidade do projeto e desempenho do edifício: uma discussão sobre o processo do projeto. In: $V$ Workshop Brasileiro de Gestão de Processo do Projeto na Construção de Edifícios, 5, 2005, Florianópolis, SC, UFSC, 2005.

SOUZA, Léa Cristina Lucas de; ALMEIDA, Manuela Guedes de; BRAGANÇA, Luís. Bê-á-bá da acústica arquitetônica. 4.ed. São Carlos: Edufscar, 2012. 